\title{
The current single exhalation method of measuring exhaled nitric oxide is affected by airway calibre
}

\author{
L.P. Ho*, F.T. Wood ${ }^{\#}$, A. Robson", J.A. Innes ${ }^{\#}$, A.P. Greening ${ }^{\#}$
}

\begin{abstract}
The current single exhalation method of measuring exhaled nitric oxide is affected by airway calibre. L.P. Ho, F.T. Wood, A. Robson, J.A. Innes, A.P. Greening. (C) ERS Journals Ltd 2000

ABSTRACT: The authors have observed that some patients with acute exacerbations of asthma do not have substantially higher levels of exhaled nitric oxide (NO). The study examined whether this could be explained by the effect of airway calibre on exhaled NO.

Exhaled NO, height and forced expiratory volume in one second (FEV1) were measured in 12 steroid-naive asthmatics and 17 normal subjects. For comparison, another group of patients with airways disease ( 34 cystic fibrosis patients) were also studied. In 20 asthmatics (on various doses of inhaled steroids, $0-3,200 \mu \mathrm{g} \cdot \mathrm{day}^{-1}$ ), exhaled NO was measured before and after histamine challenge (immediately after reaching the provocative concentration causing a $20 \%$ fall in FEV1) and in 12 of these patients, also after nebulized salbutamol to restore FEV1 to baseline. Studies were also conducted to examine possible confounding effects of repeated spirometry (as would occur in histamine challenge) and nebulized salbutamol alone in exhaled NO levels. Exhaled NO was measured using a single exhalation method with a chemiluminescence analyser at a constant flow rate and mouth pressure.

There was a significant correlation between FEV1 and exhaled NO in steroid naive asthmatics $(r=0.9, p<0.001)$ and cystic fibrosis patients $(r=-0.48, p<0.05)$ but not in normal subjects $(r=-0.13, p=0.61)$. Exhaled NO decreased significantly after histamine challenge and returned to baseline after bronchodilation by nebulized salbutamol (mean \pm SEM: 23.6 \pm 3.6 parts per billion (ppb) (prehistamine), 18.2 \pm 2.7 ppb (posthistamine) and $23.6 \pm 3.8 \mathrm{ppb}$ (postsalbutamol) $\mathrm{p}=0.001$ ). Repeated spirometry and nebulized salbutamol did not affect exhaled NO measurements significantly.

Exhaled nitric oxide levels appear to be lower in circumstances of smaller airway diameter. Hence, within a subject nitric oxide levels may be artefactually decreased during bronchoconstriction. This may be caused by increased airflow velocity in constricted airways when the exhalation rate is kept constant.
\end{abstract}

Eur Respir J 2000; 15: 1009-1013.

${ }^{\#}$ Respiratory Unit, Western General Hospital, Edinburgh, Scotland, UK. *Osler Chest Unit, Churchill Hospital, Oxford, Oxfordshire, UK.

Correspondence: L-P. Ho

Osler Chest Unit

Churchill Hospital

Headington

Oxford, OX3 7LJ

UK

Fax: 441865225221

Keywords: Airway calibre exhaled nitric oxide

Received: June 131999

Accepted after revision February 182000
Nitric oxide (NO) is a potent biological mediator with diverse physiological and pathophysiological roles [1]. In the airways, its production has been linked with airways inflammation, bronchodilatation, pulmonary vasodilatation and host defence [2]. The first of these effects (inflammation) was originally suggested by the finding of very high NO levels in the exhaled breath of asthmatics $[3,4]$. The measurement of exhaled NO has thus generated considerable interest since this may be a noninvasive and easy method of assessing airways inflammation and response to anti-inflammatory therapies. Since it was first used in 1993, the methodology of measuring exhaled NO has undergone numerous changes and improvements, culminating in the publication of a European Respiratory Society Task Force report on exhaled NO analysis in 1997 [5]. These recommendations were made, in part, as an attempt to standardize existing methods used by different laboratories. Several methods of measurement still exist and values continue to differ somewhat between the tidal reservoir collection and the single exhalation methods.
In this paper, the authors report results from studies using a single exhalation analyser which suggest that the use of a single expiratory flow rate in all patients may confound measurements of exhaled NO levels. These studies arose from anecdotal observations that: 1) not all asthmatics had increased levels of NO during the acute phase of an asthma attack; and 2) NO levels in patients with cystic fibrosis (CF) and asthma appeared to be higher with increasing forced expiratory volume in one second (FEV1). These findings prompted the question as to whether airway calibre itself affected NO levels and if this was secondary to the method of measuring exhaled NO.

\section{Materials and methods}

Study design and subjects

A two-part unblinded study was conducted. In the first part, the effect of airway calibre on exhaled NO levels in a 
cross section of asthmatics, CF patients and normal subjects were examined. The second part clarified the effect of airway diameter on exhaled NO by studying longitudinal data within asthmatic individuals.

Subjects for the first part of the study (protocol 1) comprised 12 steroid-naive asthmatics, 34 steroid-naive $\mathrm{CF}$ patients and 17 normal subjects (table 1). For protocol 2, 20 asthmatics, taking a range of doses of inhaled steroids $\left(0-3,200 \mathrm{mg} \cdot\right.$ day $\left.^{-1}\right)$, were recruited from the outpatient clinic at the Western General Hospital, Edinburgh, UK. The diagnosis of asthma was in accord with the American Thoracic Society guidelines [6] and all subjects had a provocative concentration causing a $20 \%$ fall in FEV1 (PC20) of $<16 \mathrm{mg} \cdot \mathrm{mL}^{-1}$ on bronchial provocation with histamine. All CF patients were of known CF genotype.

All recruits were nonsmokers, between the ages of 1865 yrs, and did not have upper respiratory tract infection within 4 weeks of the study or concurrent pulmonary disorders. All were clinically stable, with no changes to symptoms or treatment in the 4 weeks prior to the study.

Protocol 1: cross-sectional study on effect of forced expiratory volume in one second and height on exhaled nitric oxide

In the first group (steroid-naive patients and subjects), height, exhaled NO and FEV1 were measured (in that order) on one day and the correlations between exhaled NO levels and absolute FEV1 and per cent of predicted FEV1 examined. Steroid-naive asthmatics were recruited for this protocol to avoid the confounding and variable effect of inhaled steroids on inducible nitric oxide synthase (iNOS) activity.

Protocol 2: longitudinal study on effect of changes in forced expiratory volume in one second on exhaled nitric oxide

In the second group $(n=20)$, exhaled NO was measured immediately before and after (within $3 \mathrm{~min}$ ) a $20 \%$ decrease in FEV1 which was achieved on histamine challenge (PC20). Twelve of these subjects were then given $5 \mathrm{mg}$ salbutamol by nebulizer. FEV1 was performed after 20 min, to affirm restoration of FEV1 to prechallenge values, and exhaled NO levels were determined again.

Control studies: possible confounding effects of repeated spirometry and nebulized salbutamol

Repeated spirometric manoeuvres (as would occur during histamine challenge) have been shown to cause a reduction in NO levels $[7,8]$ and $\beta_{2}$-agonists may induce

Table 1. - Demographic data of study patients for protocol 1

\begin{tabular}{lccc}
\hline & Asthma & Normal & Cystic fibrosis \\
\hline Mean NO ppb & $18.5 \pm 8.2$ & $7.2 \pm 3.1$ & $5.0 \pm 3.2$ \\
Age yrs & $37.7 \pm 5.8$ & $34.1 \pm 11.1$ & $27.1 \pm 8.6$ \\
FEV1 \% pred & $93.4 \pm 13.6$ & $101 \pm 9.4$ & $56 \pm 23.2$ \\
\hline
\end{tabular}

Values are expressed as mean \pm SD. NO: nitric oxide; FEV1: forced expiratory volume in one second.
NO production $[7,9]$. In order to address whether the observed findings were purely related to these factors, 10 subjects in protocol 2 returned for the following studies.

In five subjects (mean FEV $1=76.6 \%$ pred, mean $\mathrm{PC}_{20}$ $=2.0 \mathrm{mg} \cdot \mathrm{mL}^{-1}$, mean change in exhaled $\mathrm{NO}$ at $\mathrm{PC} 20=$ $-24.0 \%$ ), sham histamine challenges were repeated in identical fashion with identical numbers of spirometric manoeuvres as were performed in achieving the patients' respective PC20. Exhaled NO levels were obtained before and after these repeated spirometric manoeuvres.

In the other five subjects (mean FEV $1=77.0 \%$ pred, $\mathrm{PC}_{2} 0=2.0 \mathrm{mg} \cdot \mathrm{mL}^{-1}$, mean change in exhaled $\mathrm{NO}$ at PC20 $=-23.5 \%$ ), exhaled NO was measured before and after 5 mg nebulized salbutamol to assess the contribution of salbutamol to increase in NO levels. Since nebulized salbutamol itself may cause bronchodilatation in some stable asthmatics, all subjects were given nebulized ipratropium bromide first in order to achieve maximal bronchodilatation prior to receiving salbutamol.

All time scales and manoeuvres for the two control studies were identical to protocol 2 . The study was approved by the Lothian Ethics Committee (Scotland, UK).

\section{Exhaled nitric oxide measurement}

This was performed using a single exhalation method with a sensitive chemiluminescence analyser (LR 2000; Logan Research Ltd, Rochester, Kent, UK). The analyser was calibrated daily with $\mathrm{NO} / \mathrm{N}_{2}$ calibration gas containing 103 parts per billion (ppb) NO (BOC, Guildford, Surrey, UK). All subjects exhaled at a constant rate (15 $\left.\mathrm{L} \cdot \mathrm{min}^{-1}\right)$ and maintained a constant mouth pressure of 5 $\mathrm{cmH}_{2} \mathrm{O}$ during exhalation. The mean of three readings at end expiration (plateau phase) was taken as the representative value for each measurement. The $95 \%$ confidence interval in this study is $\pm 1.72 \mathrm{ppb}$ for each measurement [10]. The method conformed optimally with European Respiratory Society guidelines on exhaled NO measurements [5].

\section{Histamine challenge}

Histamine challenge was performed using a tidal breathing method. Briefly, histamine (Tayside Pharmaceuticals, Dundee, Tayside, Scotland, UK) was delivered using a breath activated dosimeter, in doubling concentration (diluted in phosphate buffered saline) from $0.25 \mathrm{mg} \cdot \mathrm{mL}^{-1}$ until at least a $20 \%$ decrease in FEV1, compared to saline inhalation, was recorded. FEV1 was measured three times after each concentration and the best of three values was taken as the representative value.

\section{Statistical analysis}

Correlations were assessed using Pearson Product Moment Correlation test where the variables were normal or Spearman Rank Order Correlation in cases of skewed distribution. In protocol 2, the change in FEV1 and exhaled NO was analysed using a paired t-test as the exhaled NO levels were normally distributed. 


\section{Results}

\section{Protocol 1}

In the asthmatics, there was a strong positive correlation between FEV1 and exhaled NO ( $r=0.90, p<0.01$; fig. 1a). Similar findings were observed in the CF patients $(r=$ $0.48, p<0.05$; fig. $1 b)$ but not in normal subjects $(r=-0.13$, $\mathrm{p}=0.61$ ). There were no significant correlations between exhaled NO and height in any groups $(\mathrm{r}=0.2, \mathrm{p}=0.56$; $\mathrm{r}=0.11, \mathrm{p}=0.58$ and $\mathrm{r}=-0.01, \mathrm{p}=1.0$, for asthmatics, $\mathrm{CF}$ and normals respectively).

\section{Protocol 2}

There was a significant decrease in exhaled NO after histamine challenge and increase in exhaled NO after restoration of FEV1 with salbutamol: mean \pm SEM: $23.6 \pm 3.6$ $\mathrm{ppb}$ (prehistamine), $18.2 \pm 2.7 \mathrm{ppb}$ (posthistamine), and $23.6 \pm 3.8 \mathrm{ppb}$ (postsalbutamol) $(\mathrm{p}=0.001$; fig. 2$)$.

\section{Control studies}

It was found that repeated spirometry manoeuvres decreased exhaled NO levels in two out of five patients but
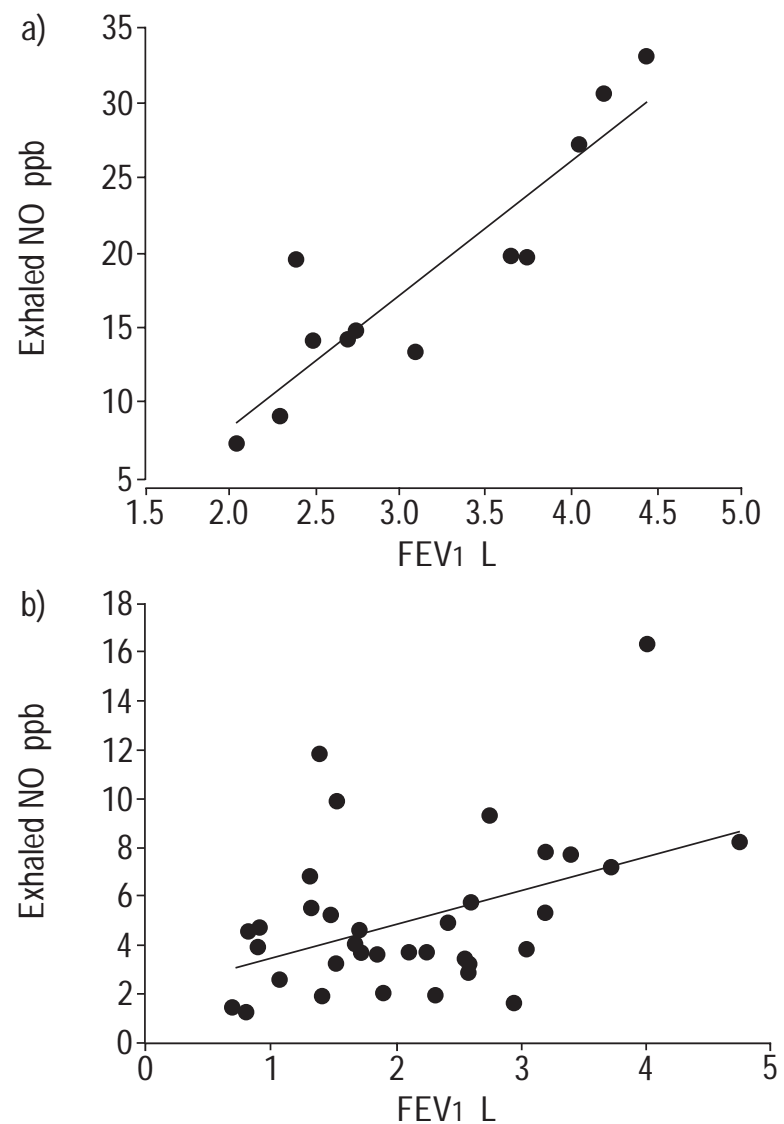

Fig. 1. - Comparison of exhaled nitric oxide (NO) and forced expiratory volume in one second (FEV1) for steroid naive asthmatics (a) and patients with cystic fibrosis (b). $\mathrm{r}=0.9, \mathrm{p}<0.01$ for asthmatics, $\mathrm{r}=0.48$, $\mathrm{p}=0.01$ for cystic fibrosis patients (Spearman Rank Order Correlation). Regression lines are shown. ppb: parts per billion.

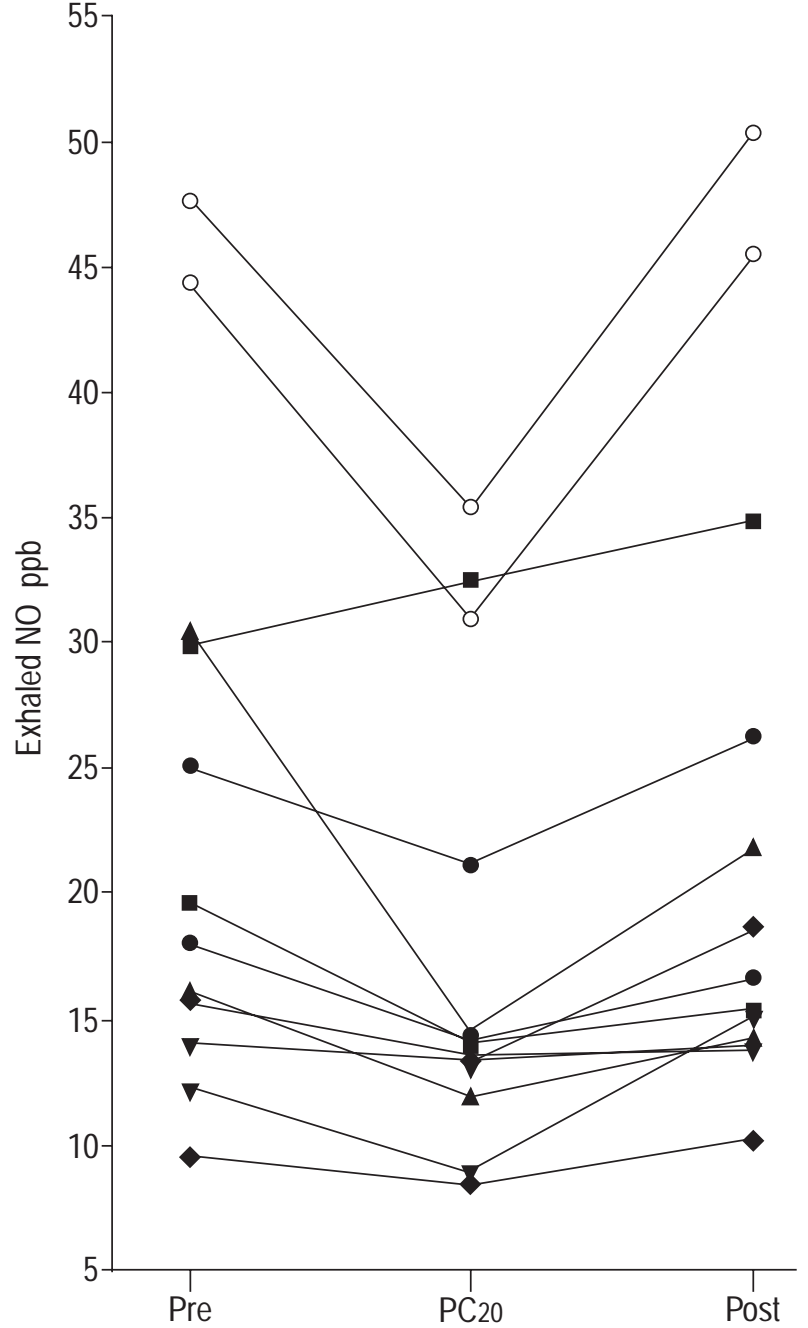

Fig. 2. - Exhaled nitric oxide (NO) expressed for individual subjects $(n=12$, since only $12 / 20$ had three time prints) before histamine challenge (pre; baseline level), immediately after the provocative concentration causing a $20 \%$ fall in forced expiratory volume in one second (FEV1; PC20) was achieved by histamine challenge (PC20) and $20 \mathrm{~min}$ after nebulization with $2.5 \mathrm{mg}$ salbutamol (post). Mean ( \pm SEM) NO was $23.6 \pm 3.6$ parts per billion (ppb) at baseline, decreasing to $18.2 \pm 2.7 \mathrm{ppb}$ after $20 \%$ drop in FEV1 and then increasing again to $23.6 \pm 3.8 \mathrm{ppb}$ after restoration of FEV1 to at least baseline FEV1.

to a much lesser extent than with histamine challenge (table 2).

Similarly, nebulized salbutamol had a very small effect on exhaled NO (apart from one patient; table 3). All changes induced by salbutamol were much less than those caused by bronchodilatation and administration of salbutamol together (table 3). In the patient where NO was increased by $21 \%$, there was an accompanying increase in FEV1 (by $14.7 \%$ ), suggesting that the change in NO levels in this patient may be contributed in large by bronchodilation. This salbutamol related bronchodilation occurred despite pretreatment with ipratropium bromide.

\section{Discussion}

The findings of this study support and extend published results on the effect of airway calibre on exhaled NO levels 
Table 2. - Individual data demonstrating the effects of repeated spirometric manoeuvres alone and during histamine challenge, on exhaled nitric oxide (NO)

\begin{tabular}{lcc}
\hline Subject No. & \multicolumn{2}{c}{ Changes in exhaled NO from baseline \% } \\
\cline { 2 - 3 } & $\begin{array}{c}\text { Histamine } \\
\text { challenge }^{+}\end{array}$ & $\begin{array}{c}\text { No histamine } \\
\text { challenge }^{\#}\end{array}$ \\
\hline 1 & -30.2 & -8.3 \\
2 & -54.5 & -28.7 \\
3 & -10.8 & -5.9 \\
4 & -5.2 & 7.9 \\
5 & -25.6 & -2.8 \\
Mean \% change & -25.3 & -7.6 \\
\hline
\end{tabular}

${ }^{+}:$At the provocative concentration causing a $20 \%$ fall in forced expiratory volume in one second (FEV1; $\mathrm{PC} 20) ;{ }^{\#}$ : after same number of repeated FEV1 manoeuvres; *: mean percentage decrease significantly greater after FEV1 manoeuvres and bronchoconstriction (PC20) compared to repeated FEV1 manoeuvres alone $(\mathrm{p}=0.01$, paired $\mathrm{t}$-test).

$[7,11,12]$. This study is the first to demonstrate the distinct relationship between FEV1 and exhaled NO levels in a cross-section of subjects with different airway diameters. Explanations for this observation include the possibility that the method of measuring exhaled NO may be responsible for an artefactual increase in exhaled NO in circumstances of larger airway diameter.

In order to overcome the confounding effect of flow rate at the mouth (which alters exhaled NO levels [13]), most single exhalation methods of measuring exhaled NO employ the use of a single exhalation rate. This means that exhalation airflow is identical $\left(250 \mathrm{~mL} \cdot \mathrm{s}^{-1}\right.$ in this case) for all subjects irrespective of their size or airway calibres. So, for a particular exhalation flow rate at the

Table 3. - Individual data on five subjects comparing the effect of nebulized salbutamol after histamine challenge and nebulized salbutamol alone on exhaled nitric oxide (NO) levels

\begin{tabular}{lccccc}
\hline $\begin{array}{l}\text { Subject } \\
\text { No. }\end{array}$ & \multicolumn{2}{c}{$\begin{array}{c}\text { Posthistamine } \\
\text { challenge* }\end{array}$} & & \multicolumn{2}{c}{$\begin{array}{c}\text { No histamine } \\
\text { challenge* }\end{array}$} \\
\cline { 2 - 3 } \cline { 5 - 6 } & $\begin{array}{c}\text { Increase in } \\
\text { FEV1 }^{\#}\end{array}$ & $\begin{array}{c}\text { Increase in } \\
\text { NO\% }^{+}\end{array}$ & & $\begin{array}{c}\text { Increase in } \\
\text { FEV }^{+}\end{array}$ & $\begin{array}{c}\text { Increase in } \\
\text { NO\%** }\end{array}$ \\
\hline 6 & 21 & 72.4 & & 14.7 & 21.0 \\
7 & 20.6 & 40.6 & & 0 & 15.5 \\
8 & 20 & 15.3 & & 4.0 & 10.9 \\
9 & 20 & 7.4 & & 4.5 & 10.3 \\
10 & 20.4 & 24.2 & & 0 & 0.0 \\
Mean & 20.4 & 32.0 & & 4.64 & 11.5 \\
\hline
\end{tabular}

For the examination of nebulized salbutamol alone, exhaled NO was measured, nebulized ipratropium bromide (IB) was given before exhaled NO levels and forced expiratory volume in one second (FEV1) were measured again. Then, nebulized salbutamol was administered, and FEV1 and exhaled NO levels measured again. Despite prior nebulization with IB, subject 6 demonstrated a $14.7 \%$ increase in FEV1 after salbutamol administration. Salbutamol nebulization alone appeared to exert some effect on NO levels but not to the degree of salbutamol and bronchodilatation. *: values measured after nebulized salbutamol; \#: compared with the provocative concentration causing a $20 \%$ fall in FEV1 (PC20); ${ }^{+}$: compared to $\mathrm{NO}$ at $\mathrm{PC}_{20}{ }^{*}$ : postcompared with presalbutamol FEV1; **: post- compared with presalbutamol. mouth, mean airflow velocity within the conducting airways will be higher when: 1) the lungs are small; and/or 2 ) the airways are constricted. When velocities are increased, exhaled gas has less "residence time" in the conducting airways, and thus less time for the airway epithelium to load the passing expirate with $\mathrm{NO}$, resulting in lower exhaled NO concentrations. This explanation would account for the findings from both protocols 1 and 2 .

It was expected that if this hypothesis was true, then exhaled NO levels would show a significant correlation with height in all three groups and with FEV1 in normal subjects. This was not the case. The lack of correlation with height is not a major challenge to the hypothesis since airway diameters may not be related directly to height, more to body size. The lack of correlation between exhaled $\mathrm{NO}$ and FEV1 in the normal subjects requires more thought. The authors think that the much smaller range of values for both FEV1 and exhaled NO may have masked possible correlations. In health, as opposed to airway diseases the range of FEV1 values is much less. Further, there is no suggestion that there are increases in NO production in normal subjects whereas there is in both asthma and CF [14]. Thus the potential range of NO values is greater in the two disease groups.

The data from the normal patients suggest that caution should be exercised when considering that airway diameter is critical in determining exhaled NO levels. However, the experiments in protocol 2 are very persuasive that it is indeed likely that airway diameter itself is important in this phenomenon. De Gouw et al. [11] who observed similar findings suggested that a decrease in surface area of the airways with bronchoconstriction might be responsible. The authors feel that this is less likely because the same number of epithelial cells will be present after bronchoconstriction although probably in a more convoluted formation. Rather, the current authors believe that the reduction after bronchoconstriction is a "false" decrease in levels caused by decrease in detection of NO. Clearly, changes in NO production by iNOS cannot explain increases and decreases over such a short period of time (30 min). Transcription of iNOS has been shown to occur as quickly as $1 \mathrm{~h}$ after stimulation [15] although a product of expression (nitrite) is maximally detectable $4-12 \mathrm{~h}$ after stimulation $[15,16]$.

Although the study has not elucidated the underlying cause for the observations, it clearly demonstrates that the degree of impairment in lung function, as measured by spirometry, appears to be correlated with higher levels of exhaled NO. This is at odds with expressed beliefs that exhaled NO levels may be an indicator of severity of airways inflammation. The reality may be that although NO production may be correlated with airway inflammation, $\mathrm{NO}$ as measured in the exhaled breath, using currently accepted methods, is an imperfect means of measuring NO production. It may not be as sensitive or specific a method for measuring NO production. Not only that, it remains confounded by a lack of complete understanding of contributions from various possible sites [17] and cellular sources of production, and as suggested by this and other studies, by changes in airway calibre and body size.

In conclusion, the findings demonstrate that exhaled nitric oxide levels are affected by airway calibre. It is suggested that the current accepted methodology for measurement of exhaled nitric oxide, which calls for one standard 
exhalation rate at the mouth for all subjects, may inadvertently result in different airflow velocities through airways with different diameters, and thus affect nitric oxide levels in exhaled breath. Hence, within each subject nitric oxide levels are artefactually decreased during bronchoconstriction.

\section{References}

1. Moncada S. NO: mediator, modulator, and pathophysiologic entity. J Lab Clin Med 1992; 120: 187-191.

2. Gaston B, Drazen JM, Loscalzo J, Stamler JS. The biology of NO in the airways. Am J Respir Crit Care Med 1994; 149: 538-551.

3. Kharitonov SA, Yates D, Springall DR, et al. Increased NO in exhaled air of asthmatic patients. Lancet 1994; 343: 133-136.

4. Alving K, Witzberg E, Lundberg JM. Increased amount of NO in exhaled air of asthmatics. Eur Respir J 1993; 6: 1368-1370.

5. Kharitonov S, Alving K, Barnes PJ. Exhaled and nasal NO measurements: recommendations. Eur Respir J 1997; 10: $1683-1693$.

6. American Thoracic Society. Standards for the diagnosis and care of patients with COPD and asthma. Am Rev Respir Dis 1987; 136: 225-244.

7. Silkoff PE, Wakita S, Chatkin J, et al. Exhaled NO after $\beta_{2}$-agonist inhalation and spirometry in asthma. $\mathrm{Am} \mathrm{J}$ Respir Crit Care Med 1999; 159: 940-944.

8. Deykin A, Halpern O, Massaro FA, Drazen JM, Israel E. Expired NO after bronchoprovocation and repeated spirometry in patients with asthma. Am J Respir Crit Care Med 1998; 157: 769-775.
9. Yates DH, Kharitonov SA, Barnes PJ. Effect of short and long acting inhaled beta 2 agonists on exhaled NO in asthmatic patients. Eur Respir $J$ 1997; 10: 14831488.

10. Ho LP, Innes JA, Greening AP. Exhaled nitric oxide is not elevated in the inflammatory airways diseases of cystic fibrosis and bronchiectasis. Eur Respir J 1998; 12: 12901294.

11. de Gouw HWFM, Hendriks J, Woltman AM, Twiss IM, Sterk PJ. Exhaled NO is reduced shortly after bronchoconstriction to direct and indirect stimuli in asthma. Am J Respir Crit Care Med 1998; 158: 315-319.

12. Granier P, Fajac JF, Dessanges JF, Dall'Ava-Santucci J, Lockhart A, Dinh-Xuan AT. Exhaled NO during acute changes of airway calibre in asthma. Eur Respir J 1996; 9: 1134-1138.

13. Silkoff PE, McClean PA, Slutsky AS, et al. Marked flowdependence of exhaled nitric oxide using a new technique to exclude nasal nitric oxide. Am J Respir Crit Care Med 1997; 155: 260-267.

14. Ho LP, Innes JA, Greening AP. Nitrite levels in breath condensate are elevated in patients with cystic fibrosis in contrast to exhaled NO. Thorax 1998; 53: 680-684.

15. Watson DN, Peroni DJ, Basclain KA, Garlepp MJ, Thompson PJ. Expression and activity of NOS in human airway epithelium. Am J Respir Cell Mol Biol 1997; 16: 629-639.

16. Robbins RA, Barnes PJ, Springall DR, et al. Expression of iNOS in human lung epithelial cells. Biochem Biophys Res Commun 1994; 203: 209-218.

17. DuBois AB, Kelley PM, Douglas JS, Mohsenin V. NO production and absorption in trachea, bronchi, bronchioles and respiratory bronchioles of humans. J Appl Physiol 1999; 86: 159-167. 